\title{
Theoretical Study of the Mechanism of Corrosion Inhibition of Carbon Steel in Acidic Solution by 2-aminobenzothaizole and 2- Mercatobenzothiazole
}

\author{
Roqaya H. Albrakaty ${ }^{1}$, Nuha A. Wazzan ${ }^{1, *}$, and I. B. Obot ${ }^{2}$ \\ ${ }^{1}$ King Abdulaziz University, College of Science, Chemistry Department, Jeddah, Saudi Arabia \\ ${ }^{2}$ Centre of Research Excellence in Corrosion, Research Institute, King Fahd University of Petroleum \\ and Minerals, Dhahran 31261, Saudi Arabia \\ *E-Mail: nwazzan@kau.edu.sa
}

doi: $10.20964 / 2018.04 .50$

Received: 11 January 2018 / Accepted: 15 February 2018 / Published: 6 March 2018

\begin{abstract}
The purpose of the present study is to provide atomic-level understanding of the mechanism of corrosion inhibition of two well-known corrosion inhibitors, 2-aminobenzothiazole (ABT) and 2mercaptobenzothiazole (MBThione), for steel in acidic media. Quantum chemical calculations and Monte Carlo simulations were the theoretical tools adopted for this study. The two inhibitors can exist in different tautomeric forms and can be protonated at different positions. Thus, quantum chemical calculations of two methods (B3LYP and MP2) with two basis sets $(6-311++\mathrm{G}(\mathrm{d}, \mathrm{p})$ and 6$311++\mathrm{G}(3 \mathrm{df}, 2 \mathrm{p}))$ were used to calculate the electronic properties of the two molecules in their different tautomeric and protonated forms. The quantitative quantum chemical parameters were correlated with experimentally determined inhibition efficiencies. Next, a correlational study addresses the relationship between the quantum chemical parameters of five electronic states and the experimentally measured inhibition efficiencies (\%IE). The results support the mixed mode of adsorption, i.e., chemisorption (the chemical model based on bonding between inhibitor and metal), preceded by physisorption (electrostatic attraction between heteroatoms and metal). Monte Carlo simulations were further applied to identify the equilibrium adsorption configurations and to compute the adsorption energy between the diazole corrosion inhibitors and the Fe surface. The results indicate that the adsorption energies follow the order: MBThione > ABT. The efficiency order and the mechanism of action of the studied inhibitors on a steel surface, as obtained by experimental results, have been verified by theoretical calculations.
\end{abstract}

Keywords: anti-corrosive; carbon steel; B3LYP and MP2 calculations; quantum chemical parameters; Monte Carlo simulation 


\section{FULL TEXT}

(C) 2018 The Authors. Published by ESG (www.electrochemsci.org). This article is an open access article distributed under the terms and conditions of the Creative Commons Attribution license (http://creativecommons.org/licenses/by/4.0/). 